\title{
Improving the energy efficiency of a piston engine based on the use of a numerical method for forming the laws of motion of gas distribution valves
}

\author{
Alexander Vasilyev ${ }^{1}$, Yulia Bakhracheva ${ }^{2^{*}}$, and Evgenij Ageev ${ }^{1}$ \\ ${ }^{1}$ Volgograd State Technical University, ${ }^{1}$ Department of heat engineering and hydraulics, 400005 \\ Prosp. Lenin, 28, Volgograd, Russian Federation \\ ${ }^{2}$ Volgograd State University, Institute of priority technologies, Department of Information Security, \\ 400062 Prosp. Universitetsky, 100, Volgograd, Russian Federation
}

\begin{abstract}
The increase in the power, economic and environmental performance of modern internal combustion engines is largely due to the improvement of the system that controls the gas exchange processes. Its characteristics determine the quality of filling and cleaning of the cylinders in various operating modes, the loss of power for gas exchange and, consequently, the indicator and effective indicators of the engine. The issues of mathematical modeling of gas exchange processes in combination with the study and improvement of the gas distribution mechanism are considered. The results of experimental and computational studies of gas exchange of tractor diesel are presented. Reserves for improving the gas exchange and the engine as a whole are identified based on the choice of optimal valve timing phases and valve motion laws. They provide a reduction in the modulus of the average pressure of the pump passages in the range of operating modes by $12-14 \%$, which contributed to a decrease in the specific effective fuel consumption by $1.4 \div 2.2 \mathrm{~g} / \mathrm{kWh}$. The above allows us to conclude that the use of a generalized step-by-step numerical method for synthesizing the law of motion of a pusher with an upper stand allows us to obtain the maximum efficiency characteristics of the gas distribution in the presence of a number of restrictions.
\end{abstract}

\section{Introduction}

The increase in the power, economic and environmental performance of modern internal combustion engines is largely due to the improvement of the system that controls the gas exchange processes. Its characteristics determine the quality of filling and cleaning of the cylinders in various operating modes, the loss of power for gas exchange and, consequently, the indicator and effective indicators of the engine. Indeed, the valve gap is the main source of aerodynamic resistances in the channels of the cylinder head: it accounts for up to $75-90 \%$ of the total channel resistance [1].

*Corresponding author: bakhracheva@ volsu.ru 
In this regard, the area under the curve of its movement Fs, associated with the value of the time-section of the valve, is usually taken as a criterion indicator when choosing the law of movement of the valve pusher. A number of studies have investigated the effect of this criterion on the effective performance of the engine. Thus, in [2 - 11], in particular, it is shown that by increasing the valve cross-section by $13-15 \%$, a decrease in the specific effective fuel consumption by $2.533 \mathrm{~g} / \mathrm{kWh}$ can be obtained.

The numerical method of mathematical modeling of gas exchange processes in combined internal combustion engines allows us to establish the relationship between the working processes in the gas-air path and the parameters and characteristics of the gas distribution mechanism (gas distribution phases, the law of movement of the pusher, flow sections at the inlet and outlet, gear ratios, thermal gaps, the number of valves). This relationship is the basis for optimizing the elements of the gas distribution mechanism. This takes into account the change in the composition of the working fluid in the cylinders during the gas exchange period, taking into account possible backflows from the cylinders to the intake channels and from the exhaust channels to the cylinders, which provides a more accurate determination of the gas exchange indicators.

The advantages of this method consist, firstly, in the possibility of constructing design schemes of piston and combined engines in an automated mode based on the specified initial data that determine the required structure of the gas-air path, as well as the number and parameters of its elements. Thus, the model does not impose restrictions, for example, on the number of cylinders, turbochargers, elements that model the collector, the charge air cooler, as well as on the order of operation of the cylinders and the connection scheme of the elements of the gas-air path. Secondly, the closed calculation of the working processes of reciprocating and combined internal combustion engines, the determination of the parameters of the working fluid in the gas-air path, gas exchange indicators, indicator and effective indicators of the engine can be performed both in a quasi-stationary setting, and taking into account the non-stationary nature of gas-dynamic processes. At the same time, there are no restrictions on the number of elements in which processes are considered as quasi-stationary or non-stationary, and on the possibility of their connections with each other.

\section{Mathematical model}

The algorithm for forming the law of motion of a pushrod with an upper stand allows us to obtain discontinuous acceleration curves (including those with a limited jump value of the latter) by appropriately setting the boundary conditions at the top of the cam. Below is a comparative analysis of the results of profiling the cam of a diesel engine in two ways.

1. A three-arc concave cam obtained using a mathematical model for the central cam mechanisms of the valve drive [12]. In order to select the profile parameters that provide the longest time-section of the valve, mathematical methods of experiment planning were used in the construction of this model. In this regard, it should be assumed that the cam described in [13-16] is characterized by the highest efficiency for this profiling method and specific source data.

2. The cam, profiled using the considered step-by-step numerical method of forming the law of motion of the pusher.

Initial data: the speed of the camshaft-500 rpm, the maximum movement of the pusher$20 \mathrm{~mm}$, the initial radius of the cam circumference- $42 \mathrm{~mm}$, the radius of the pusher roller$28 \mathrm{~mm}$, the total angle of action on the sides of lifting or lowering, taking into account the upper stand and the selection of the thermal gap-79 degrees. The minimum radius of curvature of the concave section of the profile is $160 \mathrm{~mm}$. 


\section{EEESTS-2021}

According to the first method, the following results were obtained: the radius of the concave section of the profile - $164 \mathrm{~mm}$, the radius of the convex section - $32 \mathrm{~mm}$, the radius of the upper stand $-62 \mathrm{~mm}$, the length of the positive acceleration section - 16 degrees, the length of the upper stand - 12 degrees. The dependences of the analog of the pusher acceleration and the radius of curvature of the profile on the angle of rotation of the cam are shown in Figure 1 in solid lines. The value of the completeness coefficient of the pusher displacement diagram was 0.635 .

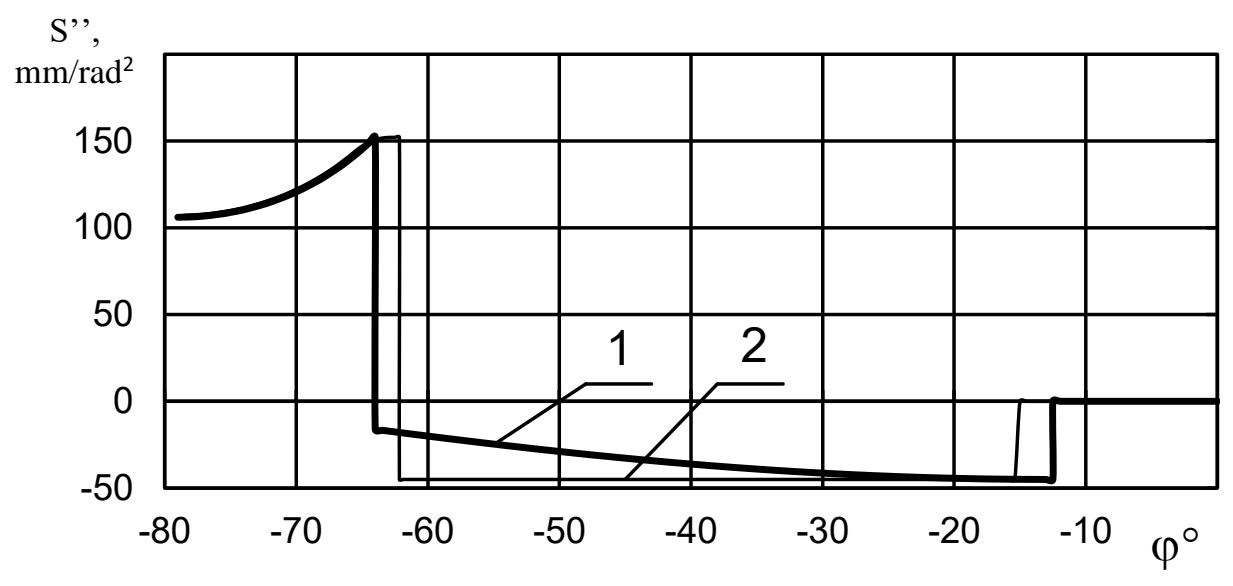

a)

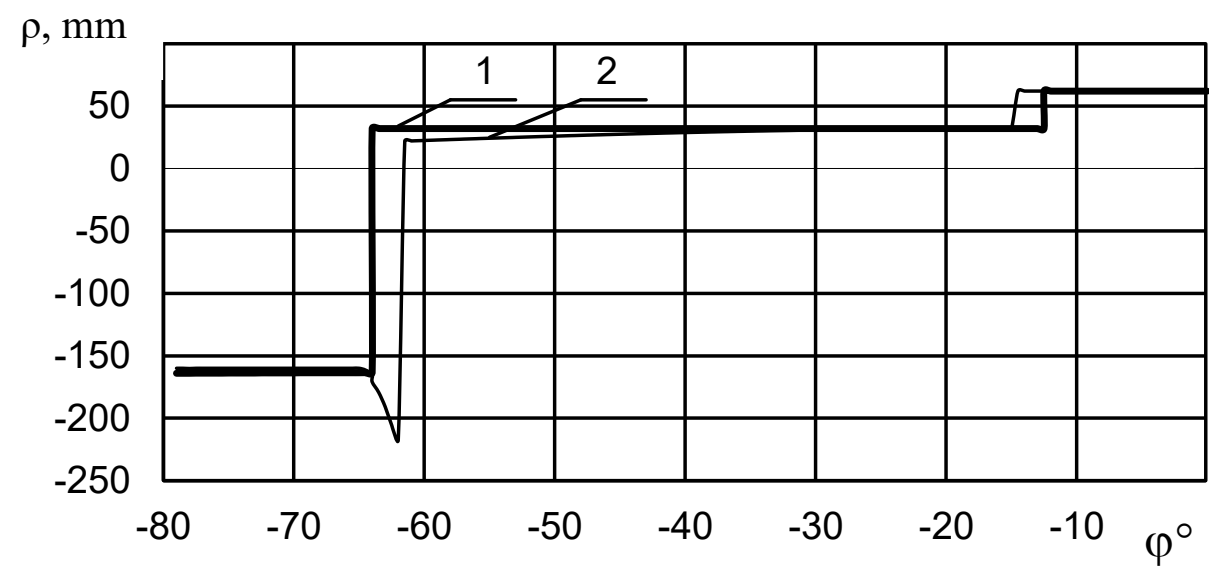

b)

Fig. 1. Analogous to the acceleration of the pusher (a) and the radius of curvature of the cam profile (b) by the angle of its rotation: 1 - three-arc; 2-profiled on the basis of the numerical method

In Figure 1, the dashed lines show the characteristics of the cam, profiled with the same initial data on the basis of a step-by-step numerical method for forming the law of motion of the pusher. In this case, the limits on the acceleration analog were chosen to be equal to the corresponding maximum values for the three-arc cam profile. So, for the entire area of changing the angle of rotation of the cam $\varphi$, corresponding to the working section of the profile $-45 \mathrm{~mm} / \mathrm{rad}^{2} \leq \mathbf{s}^{\prime \prime} \leq 152 \mathrm{~mm} / \mathrm{rad}^{2}$.

In addition, when profiling, a restriction on the radius of curvature of the concave section of the profile (at least $160 \mathrm{~mm}$ ) was also used. 


\section{Discussion}

In the course of numerical experiments, when varying all phases of the gas distribution, gas exchange indicators (coefficients of air flow, filling, residual gases), pump losses, indicator and effective indicators of the engine were determined. Calculations were made in the range of operating modes of the engine at $n=1500 \div 1850 \mathrm{rpm}$, taking into account the prospect of forcing the engine at the speed of the crankshaft. As a result, the optimal timing phases and profiles of the intake and exhaust cams for increased reliability and efficiency were determined. They provide a reduction in the modulus of the average pressure of the pump passages in the range of operating modes by $12-14 \%$, which contributed to a decrease in the specific effective fuel consumption by $1.4 \div 2.2 \mathrm{~g} / \mathrm{kWh}$. At the same time, larger numbers correspond to higher crankshaft speeds. It is important to note that these results are achieved without reducing the gas exchange indicators that determine the quality of filling and cleaning of cylinders. Thus, in the nominal engine operation mode, the excess air coefficient $\alpha$ is approximately 2.2 with both the serial and recommended cams at the same hourly fuel consumption $\mathrm{G}_{\mathrm{t}}=67 \mathrm{~kg} / \mathrm{h}$. And the filling factor is even slightly increased (by about $1 \%$ ). The angular length of the recommended intake cam is slightly less than the standard one (by $3^{\circ}$ of the crankshaft rotation angle), and the exhaust cam is larger (by $7^{\circ}$ of the crankshaft rotation angle). At the same time, the time-section of the recommended intake cam is approximately 5\% larger than the serial one, and the exhaust cam is $10 \%$ larger. The recommended valve timing phases differ markedly from the standard ones: the intake cam has a reduced closing delay angle from $58^{\circ}$ to $44^{\circ}$ and, accordingly, an increased opening advance angle from $24^{\circ}$ to $36^{\circ}$. At the exhaust cam, both phases are increased: the opening advance angle from $74^{\circ}$ to $80^{\circ}$, the closing delay angle from $22^{\circ}$ to $24^{\circ}$. As can be seen from the above data, when using the recommended cams, the overlap of the valves increases slightly. This allows you to increase the time-section of the valves, and, as calculations have shown, ultimately ensure a high-quality flow of the gas exchange process in combination with the high dynamic qualities of the valve drive. In addition, the movement of the valves in the area of the upper dead center is small, and the increase in overlap does not have a noticeable negative effect on the quality of cleaning and filling of the cylinders. Further improvement of gas exchange can be associated with a reduction in the resistance of the gas-air path and a rational choice of turbocharging elements.

\section{Conclusion}

As a result, it is obtained that only due to the optimal redistribution of the values of the pusher acceleration at the same length, the value of the coefficient of completeness of the displacement diagram increased to 0.656. It should also be noted that when using the method [14], the choice of parameters of the three-arc profile is made only taking into account the restriction on the radius of the concave section. Therefore, the restrictions adopted for the step-by-step method $-45 \mathrm{~mm} / \mathrm{rad}^{2} \leq \mathbf{s}^{\prime \prime} \leq 152 \mathrm{~mm} / \mathrm{rad}^{2}$ are not related to its service characteristics. If the requirements, for example, for drive dynamics or contact voltage, allow to mitigate these limitations, the efficiency of the valve timing characteristics can be further increased. The above allows us to conclude that the use of a generalized stepby-step numerical method for synthesizing the law of motion of a pusher with an upper stand allows us to obtain the maximum efficiency characteristics of the gas distribution in the presence of a number of restrictions. At the same time, it is possible to change the smoothness of the pusher acceleration curve within a wide range during the system design process in accordance with its operating modes. 
The reported study was funded by RFBR and the government of Volgograd region according to the research project № 19-48-340015 p_a.

\section{References}

1. A.I. Leontiev, R.Z. Kavtaradze, D.O. Onishchenko, A.S. Golosov, S.A. Pankratov Improvement of piston engine operation efficiency by direct conversion of the heat of exhaust gases into electric energy High Temperature, 54 (1), 105-112 (2016)

2. R.Z. Kavtaradze, D.O.Onishchenko, A.A. Zelentsov, S.S. Sergeev The Influence of Rotational Charge Motion Intensity on Nitric Oxide Formation in Gas-Engine Cylinder International Journal of Heat and Mass Transfer, 52, 4308 (2009)

3. B.F. Magnussen, B.H. Hjertager On Mathematical Models of Turbulent Combustion with Special Emphasis of Soot Formation and Combustion 16th Int. Sympos. on Combustion. Cambrige p. 719 (1976)

4. K. Hanjali, M. Popova, M. Hadziabdi, A. Robust Near Wall Elliptic Relaxation Eddy Viscosity Turbulence Model for CFD Int. J. Heat Fluid Flow, 25, 897 (2004)

5. D. Pashchenko Energy optimization analysis of a thermochemical exhaust gas recuperation system of a gas turbine unit Energy Conversion and Management, 171, 917-924 (2018)

6. G.P. Olmsted Heat engine efficiency enhancement-through chemical recovery of waste heat 7th Intersociety Energy Conversion Engg. Con, 241-248 (1972)

7. C. Gaber et al. An experimental study of a thermochemical regeneration waste heat recovery process using a reformer unit Energy, 155, 381-391 (2018)

8. L. Chen, T. Zheng, F. Sun, C.Wu The power and efficiency characteristics for an irreversible Otto cycle International Journal of Ambient Energy, 24(4), 195-200 (2003)

9. F.Angulo-Brown An ecological optimization criterion for finitetime heat engines Journal of Applied Physics, 69(11), 7465-7469 (1991)

10. Cheng Ching-Yang, Chen Cha'o-Kung The ecological optimization of an irreversible Carnot heat engine J. Phys. D: Appl Phys, 30(1), 1602-1609 (1997)

11. Yan Zijun, Lin Guoxing Ecological optimization criterion for an irreversible three-heat source refrigerator Applied Energy, 66(3), 213-224 (2000)

12. A. V. Vasilyev et al. Dynamics simulation model for the internal combustion engine valve gear Procedia engineering, 150, 312-317. doi:10.1016/j.proeng.2016.07.017 (2016)

13. A. Vasilyev, Y. Bakhracheva Determination of the Internal Combustion Engines Valve Gear Characteristics IOP Conf Series: Journal of Phisics: Conf. Series, 1050, 012094 doi: 10.1088/1742-6596/1050/1/012094 (2018)

14. Y.Bakhracheva Development of Absorbing Coatings for Protection Against Electromagnetic Pollution of the Environment IOP Conference Series: Materials Science and Engineering, 680(1), 012024 (2019)

15. A.V. Vasilyev, Y.S. Bakhracheva Calculation of kinematic characteristics of internal combustion engine valve gear Lecture Notes in Mechanical Engineering 0(9783319956299). 393-399 (2019) 